\title{
Research on current situation of cultural development and future development trend of "South Lion"
}

\author{
Shihai Liu* \\ Institute of Physical Education, Hubei Normal University, Wuhan, Hubei, China
}

\begin{abstract}
This paper obtains the influence factors of cultural development of South Lion through the construction of a multi-index fixed-weight hierarchical structure model, analysis of cultural development issues of South Lion in China, and the relevant survey. This paper subsequently proposes a more effective structure optimization program through fixed-weight analysis and combined with the limitations of cultural development. That is, the future development strategies of South Lion in China should be as follows: to construct the public cultural development system of South Lion, regulate the cultural education of South Lion, and increase the courses offered, develop the public interest and cultivate the talents and strengthen the culture commercial development of South Lion.
\end{abstract}

Keywords: South Lion culture; development status; research on future development trend

\section{INTRODUCTION}

China is a civilized country with more than 5,000 years of history, and its inherited culture is endless, and full of China's national spirit. After the reform and opening up, China opens up the socialist road with Chinese characteristics for the development, and China's economy and comprehensive national strength also has an increasingly important impact on the international arena. With an increasingly extensive national and international exchange, China's cross- border economic transactions are increasingly intense, and the cross-cultural communication between civilizations is of the trend.

With the economic development, many industries have obtained a larger space for development. Coupled with the information development in society, and integration with the Internet and industries, the industries can display their characteristic vitality through the combination with diversified elements, including the industry full of the sportsmanship and cultural heritage. However, due to the emphasis of the national development and limitation in the development of some industries, the development of the regional national culture movement full of China's unique national spirit and the traditional culture is very slow, and even the danger of inheritance exists in the essence of some culture. The main reason is that, nowa- days, with the main objective of economic development, the population who protects and inherits the national intangible cultural heritage and national tradition is becoming increasingly scarce. However, these culture and athletic sports with the national traditional spirit has a very important significance on the inheritance of the nation and even the country's history and culture, of which China's dragon dance and lion dance is one of the athletic sports recognized by the world, and represents the culture of China's national spirit. However, due to strong territoriality, difference, and many problems in the internal cultural development of lion dance, China's cultural development and inheritance of lion dance have many difficulties.

Therefore, this paper will establish a multi-index fixed-weight structure model based on China's cultural development and inheritance of lion dance, and make a detailed quantifiable assessment and analysis of future development trend and development points by taking South Lion Culture as an example, and find out the optimal development programs.

\section{RELEVANT RESEARCH OF CULTURAL DEVELOPMENT OF "SOUTH LION"}

Due to the difference in lion dance culture in different regions, and difference in the ideology of North and 
South Lion Dance culture, the lion dance culture has its own school, resulting in unstable development, so that the extraction of the essence of lion dance culture and integration with elements in a new era becomes very difficult. China attaches great importance to the protection of national culture, but the cultural development of South Lion is slow due to defects and limitations in the culture inheritance of lion dance, and the lack of extensive education of South Lion. Nowadays, with the development of the Internet information throughout the world, all kinds of sporting events is also rapidly developing through the integration with diversified elements, including the South Lion culture. As a national traditional sporting event inheriting the lion dance culture, South Lion encounters some obstacles and difficulties in the development process in a new era. However, the cultural development of South Lion has a very important significance on the inheritance of China's national history. Therefore, the research of the South Lion culture becomes the research focus of cultural heritage of lion dance.

In recent years, the academic community carries out a lot of research and analysis of the cultural heritage of South Lion, including the research of the cultural development and development trend of South Lion. For example, the paper published by Jiang Xiping ${ }^{[1]}$ in 2007 makes a detailed analysis of the development history and current development trend of South Lion; in 2012, Li Limin ${ }^{[2]}$ demonstrated the current development trend and situation of South Lion culture by taking the example of Teng County; in 2015, Liu Guoping ${ }^{[3]}$ carries out a macroscopic evaluation of the lion dance culture through comparison with the difference between South Lion culture and North Lion culture. There are many researches of the educational development of South Lion culture. For example, in 2009, Hu Xin ${ }^{[4]}$ researched the offered situation and current status of the lion dance culture course in universities through statistical survey; in 2010 Long Yizhi ${ }^{[5]}$ proposed an extensive teaching program of the lion dance culture in universities. There are also many researches of the cultural athletic development of South Lion. For example, in 2013, Zhao Feng ${ }^{[6]}$ proposed the current situation of lion dance culture and athletics system strategies via coordinated development. However, the research of the difficulties and influence factors of the cultural development of South Lion is more general, without specifically pointing out the reasons affecting the cultural development of South Lion and relationship between systems development. This paper establishes a multi-index fixed-weight hierarchical structure model based on the quantifiable analysis and researches the future development direction of the South Lion culture, in order to preferably solve the above-mentioned issues.

\section{QUANTIFIABLE FIXED-WEIGHT ASSESS- MENT OF CULTURAL DEVELOPMENT OF "SOUTH LION"}

The quantifiable fixed-weight hierarchical structure model can be empowered according to a lot of references and experience of relevant experts, thus finding out a practical solution. This paper points out that the research of the difficulties and influence factors of the cultural development of South Lion is not enough today, but has a great impact on the cultural development of South Lion. Therefore, this paper establishes a multi-index fixed-weight hierarchical structure model based on the quantifiable analysis and researches the future development direction of the South Lion culture, in order to preferably solve the above-mentioned issues. This paper first finds out the obstacles in the

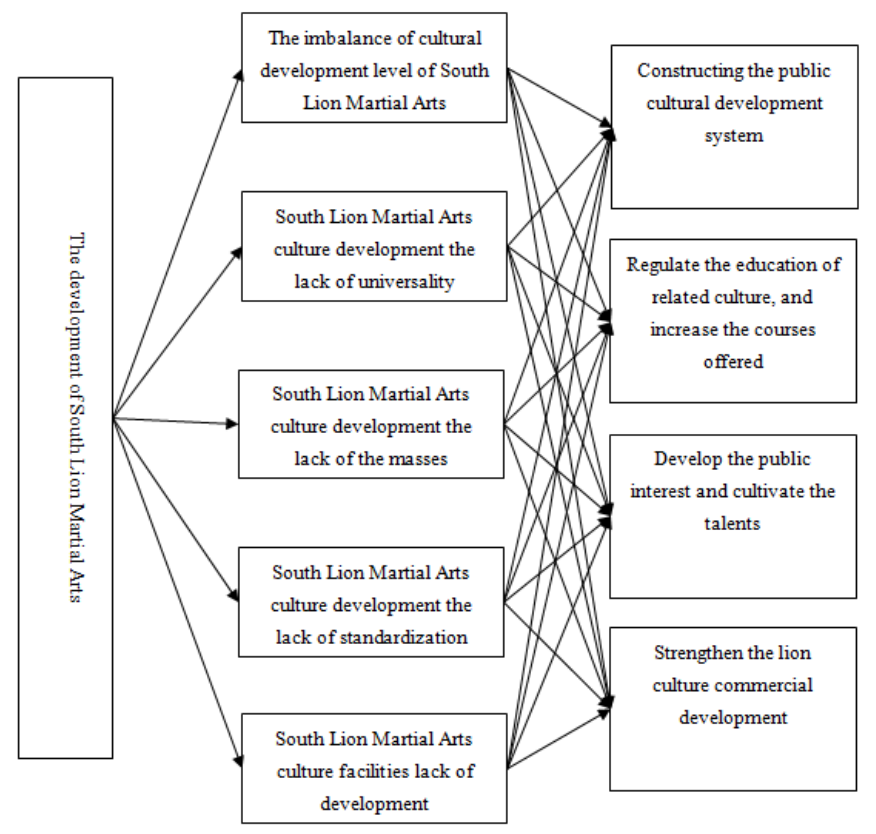

Figure 1. Hierarchical structure 
process of cultural development of South Lion, and then establishes a multi-index fixed-weight hierarchical structure analysis model, and quantifies the origins and solving strategies of various problems, and establishes the index hierarchical structure relationship.

Target layer: development of South Lion culture.

Criteria layer: $x_{1}$ is the imbalance of cultural development level of South Lion, $x_{2}$ is the lack of universality in the cultural development of South Lion, $x_{3}$ is the lack of the masses in the cultural development of South Lion, $x_{4}$ is the lack of standardization in the cultural development of South Lion, $x_{5}$ is the lack of development of facilities in the cultural development of South Lion.

Scheme layer: $y_{1}$ is to construct the public cultural development system of South Lion, $y_{2}$ is to regulate the cultural education of South Lion, and increase the courses offered, $y_{3}$ is to develop the public interest and cultivate the talents, and $y_{4}$ is to strengthen the culture commercial development of South Lion. The hierarchical structure chart is shown in Figure 1.

According to a large number of experiences of experts, and with reference to the extensive literature, as well as the scale from 1 to 9 , the pairwise comparison matrices can be obtained, as shown in Table 1-2.

Table 1. Comparison matrix

\begin{tabular}{l|lllll}
\hline $\mathrm{G}$ & $x_{1}$ & $x_{2}$ & $x_{3}$ & $x_{4}$ & $x_{5}$ \\
\hline$x_{1}$ & 1 & $1 / 4$ & 3 & 5 & 3 \\
$x_{2}$ & 4 & 1 & 5 & 4 & 3 \\
$x_{3}$ & $1 / 3$ & $1 / 5$ & 1 & 3 & $1 / 2$ \\
$x_{4}$ & $1 / 5$ & $1 / 4$ & $1 / 3$ & 1 & $1 / 2$ \\
$x_{5}$ & $1 / 3$ & $1 / 3$ & 2 & 2 & 1 \\
\hline
\end{tabular}

According to the formula, $C I=\frac{\lambda_{\max }-n}{n-1}$, to calculate $C I$, and obtain analysis consistency, and finally obtain rational consistency of $C$, that is, the judgment matrix passes the consistency test by the use of the above principle.

$$
\begin{gathered}
C_{1}=\left\{\begin{array}{cccc}
1 & 4 & 4 & 3 \\
1 / 4 & 1 & 2 & 3 \\
1 / 4 & 1 / 2 & 1 & 4 \\
1 / 3 & 1 / 3 & 1 / 4 & 1
\end{array}\right\}, C_{2}=\left\{\begin{array}{cccc}
1 & 1 / 5 & 4 & 3 \\
5 & 1 & 3 & 2 \\
1 / 4 & 1 / 3 & 1 & 1 / 3 \\
1 / 3 & 1 / 2 & 3 & 1
\end{array}\right\}, C_{3}=\left\{\begin{array}{cccc}
1 & 2 & 4 & 4 \\
1 / 2 & 1 & 2 & 3 \\
1 / 4 & 1 / 2 & 1 & 2 \\
1 / 4 & 1 / 3 & 1 / 2 & 1
\end{array}\right\} \\
C_{4}=\left\{\begin{array}{cccc}
1 & 3 & 3 & 1 / 4 \\
1 / 3 & 1 & 1 / 3 & 4 \\
1.3 & 3 & 1 & 3 \\
4 & 1 / 4 & 3 & 1
\end{array}\right\}, C_{5}=\left\{\begin{array}{cccc}
1 & 3 & 5 & 6 \\
1 / 3 & 1 & 1 / 2 & 4 \\
1 / 5 & 2 & 1 & 3 \\
1 / 6 & 1 / 4 & 1 / 3 & 1
\end{array}\right\}
\end{gathered}
$$

To test the rationality of weight value by the use of consistency index:

$C I=\frac{\lambda_{\max }-n}{n-1}, \quad C R=\frac{C I}{R I}$

RI can be obtained as shown in Table 3 .

Table 3. RI values

\begin{tabular}{|l|l|l|l|l|l|l|l|l|l|l|l|}
\hline $\mathrm{n}$ & 1 & 2 & 3 & 4 & 5 & 6 & 7 & 8 & 9 & 10 & 11 \\
\hline $\mathrm{RI}$ & 0 & 0 & 0.58 & 0.90 & 1.12 & 1.24 & 1.32 & 1.41 & 1.45 & 1.49 & 1.51 \\
\hline
\end{tabular}

obtaining the judgment matrix $G$,

$\lambda_{\text {max }}^{(0)}=4.15, R I=0.9$

$C I=\frac{4.15-4}{4-1}=0.24$

$C R=\frac{C I}{R I}=\frac{0.024}{0.90}=0.027<0.1$

The result is less than 0.1 , indicating that the consistency test result of $G$ is rational, and is allowed to move within the permissible range, so that the eigenvector solved by the matrix $G$ can be described as the weight vector. The computing results from the target layer to the scheme layer can be obtained by the consistency test of the judgment matrix, as shown in Figure 2.

\begin{tabular}{|c|c|c|c|c|c|c|c|c|c|}
\hline$x_{1}$ & $y_{1}$ & $y_{2}$ & $y_{3}$ & $y_{4}$ & $x_{2}$ & $y_{1}$ & $y_{2}$ & $y_{3}$ & $y_{4}$ \\
\hline$y_{1}$ & 1 & 4 & 4 & 3 & $y_{1}$ & 1 & $1 / 5$ & 4 & 3 \\
\hline$y_{2}$ & $1 / 4$ & 1 & 2 & 3 & $y_{2}$ & 5 & 1 & 3 & 2 \\
\hline$y_{3}$ & $1 / 4$ & $1 / 2$ & 1 & 4 & $y_{3}$ & $1 / 4$ & $1 / 3$ & 1 & $1 / 3$ \\
\hline$y_{4}$ & $1 / 3$ & $1 / 3$ & $1 / 4$ & 1 & $y_{4}$ & $1 / 3$ & $1 / 2$ & 3 & 1 \\
\hline$x_{3}$ & $y_{3}$ & $y_{2}$ & $y_{3}$ & $y_{4}$ & $x_{4}$ & $y_{1}$ & $y_{2}$ & $y_{3}$ & $y_{4}$ \\
\hline$y_{1}$ & 1 & 2 & 4 & 4 & $y_{1}$ & 1 & 3 & 3 & $1 / 4$ \\
\hline$y_{2}$ & $1 / 2$ & 1 & 2 & 3 & $y_{2}$ & $1 / 3$ & 1 & $1 / 3$ & 4 \\
\hline$y_{3}$ & $1 / 4$ & $1 / 2$ & 1 & 2 & $y_{3}$ & $1 / 3$ & 3 & 1 & 3 \\
\hline$y_{4}$ & $1 / 4$ & $1 / 3$ & $1 / 2$ & 1 & $y_{4}$ & 4 & $1 / 4$ & $1 / 3$ & 1 \\
\hline$x_{5}$ & & $y_{1}$ & & $y_{2}$ & & $y_{3}$ & & $y_{4}$ & \\
\hline$y_{1}$ & & 1 & & 3 & & 5 & & 6 & \\
\hline$y_{2}$ & & $1 / 3$ & & 1 & & $1 / 2$ & & 4 & \\
\hline$y_{3}$ & & $1 / 5$ & & 2 & & 1 & & 3 & \\
\hline$y_{4}$ & & $1 / 6$ & & $1 / 4$ & & $1 / 3$ & & 1 & \\
\hline
\end{tabular}

Table 2. Comparison matrix 


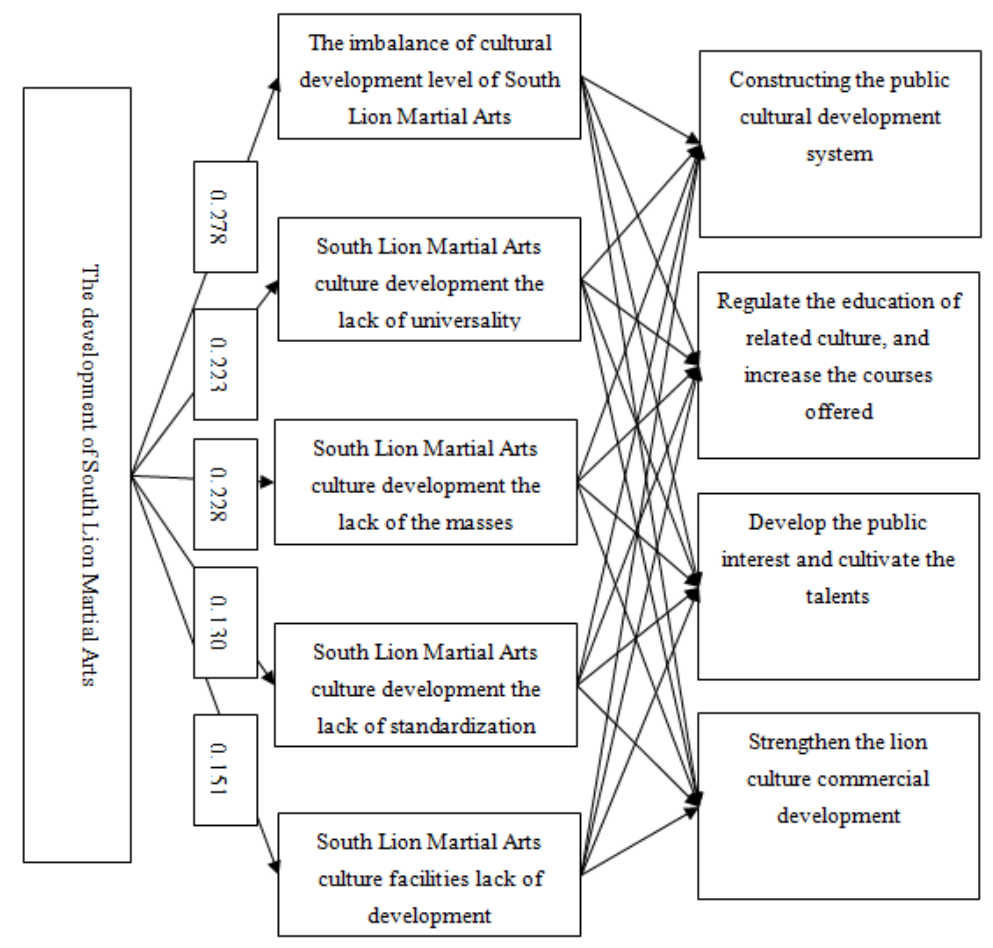

Figure 2. Computing results from the target layer to the scheme layer

Computing structure is as follows:

$$
\begin{aligned}
i^{(1)} & =\left(i^{(1)}{ }_{1}, i^{(1)}{ }_{2}, i^{(1)}{ }_{3}, i^{(1)}{ }_{4}, i^{(1)}{ }_{5}\right) \\
& =\left\{\begin{array}{lllll}
0.163 & 0.203 & 0.224 & 0.293 & 0.218 \\
0.395 & 0.302 & 0.232 & 0.224 & 0.335 \\
0.345 & 0.312 & 0.323 & 0.211 & 0.221 \\
0.187 & 0.193 & 0.221 & 0.272 & 0.223
\end{array}\right\}
\end{aligned}
$$

$i=i^{(1)} i^{(0)}$

$$
=\left\{\begin{array}{lllll}
0.163 & 0.203 & 0.224 & 0.293 & 0.218 \\
0.395 & 0.302 & 0.232 & 0.224 & 0.335 \\
0.345 & 0.312 & 0.323 & 0.211 & 0.221 \\
0.187 & 0.193 & 0.221 & 0.272 & 0.223
\end{array}\right\}\left\{\begin{array}{l}
0.278 \\
0.223 \\
0.228 \\
0.130 \\
0.151
\end{array}\right\}=\left\{\begin{array}{l}
0.312 \\
0.224 \\
0.240 \\
0.224
\end{array}\right\}
$$

According to the analysis of the future development direction of the South Lion culture in China through the establishment of multi-index fixed-weight hierarchical structure model, the research of the difficulties and influence factors of the cultural development of South Lion is not enough today, but has a great impact on the cultural development of South Lion. Therefore, after the relevant survey, the influence factors of the cultural development of South Lion mainly include the following aspects, namely, the imbalance of cultural development level of South Lion, the lack of universality in the cultural development of South Lion, the lack of the masses in the cultural development of South Lion, the lack of standardization in the cultural development of South Lion, and the lack of development of facilities in the cultural development of South Lion, with the weight of respectively $0.278,0.223$,
$0.228,0.130$ and 0.151 . After the weight analysis, the future development strategies of South Lion in China should be as follows: to construct the public cultural development system of South Lion, regulate the cultural education of South Lion, and increase the courses offered, develop the public interest and cultivate the talents and strengthen the culture commercial development of South Lion, with the weight of respectively $0.312,0.224,0.240$ and 0.224 .

\section{CONCLUSION}

This paper first analyzes the current situation of cultural development of South Lion and shortcomings of scientific research, and then proposes a more effective structure optimization program through the construction of the multi-index fixed-weight hierarchical structure model, analysis of cultural development issues of South Lion in China and combined with the limitations of cultural development. In this way, we can clearly reveal the difficulty in solving obstacles in the process of cultural development, and find out the reasons affecting the cultural development of South Lion and the importance of relationship between systems development. The multi-index fixed-weight hierarchical structure model adopted in this paper can macroscopically analyze the relationship between the cultural development issues of South Lion and solutions to future development. The game analysis of coordinated development between South Lion culture and North Lion culture is a research direction with more practical values. 


\section{ACKNOWLEDGEMENT}

This paper is funded by the Wushu Research Institute of General Administration of Sport (Project No. WSH2015Q018).

\section{REFERENCES}

[1] Jiang Xiping. 2007. Research on Historical Culture and Development Status of "South Lion". South China Normal University,

[2] Li Limin. 2012. Research on Inheritance and Development of South Lion - A case study of Lion dance in Teng County. Guangxi University for Nationalities, 4, 1.

[3] Liu Guoping. 2015. Comparative research of cultural development of South Lion and North Lion. Sports Goods and Technology, 5, 15.
[4] Hu Xin. 2015. Investigation and Research on Offering Status of Dragon Dance and Lion Dance Course in Wuhan Institute of Physical Education. Wuhan Institute of Physical Education, 5, 1.

[5] Long Yizhi. 2010. Research on Promotion Strategy of College Dragon and Lion Dance. Central South University, 6,30 .

[6] Zhao Feng. 2013. Research on the Technology System of the Athletics Lion Dance. Hunan Normal University, 5.

[7] Guan Luohong. 2011. Analysis of China's lion dance and cultural value. Entrepreneur World (Theory), (1).

[8] Zhang Xiaohong, Xu Wen. 2012. Exploration of the value of lion dance in national traditional sports. Hubei Sports Science, (3).

[9] Yun Xin, Liu Mintao. 2013. Development of Chinese lion dance and school screening. People's Forum, (2).

[10] Li Chunxiang. 2014. Comparative analysis and combination with lion dance and traditional martial arts. Sports, (21). 